\title{
Discourse, identity and change in mid-to-late life: interdisciplinary perspectives on language and ageing
}

\author{
JUSTINE COUPLAND*
}

\begin{abstract}
The papers in this special issue contribute to the growing body of research on sociolinguistic and discursive interpretations of mid and later life by investigating some of the identity affordances and constraints associated with 'being middleaged' or 'being old'. The papers here offer qualitative, contextually based analyses of a broad range of data and use various methodological and theoretical perspectives: narrative theory, critical pragmatics, social theory and discursive psychology. The main focus is on the ways in which change impacts on the ageing individual, and how this change is discursively interpreted and negotiated both by and for or about individuals in diverse social frames. We examine age and change as they interact with personal and social identity in personal diary accounts, in print, on the television and web media, in conversations amongst friends and acquaintances, in interviews and during storytelling. Language and communication are examined as resources for making and interpreting the meanings of ageing, at both the macro (societal) and micro (individual and inter-personal) levels.
\end{abstract}

$\boldsymbol{K E Y} \boldsymbol{W} \boldsymbol{O} \boldsymbol{R} \boldsymbol{D} \boldsymbol{S}$ - meanings of ageing, qualitative approaches, talk, text, change, identity.

In I99 I two colleagues and I published a monograph titled Language, Society and the Elderly (Coupland, Coupland and Giles I99I). Its sub-title, Discourse, Identity and Ageing, was not greatly different from the title of this thematic issue, Discourse, Identity and Change in Mid-to-Late Life. We presented our book as a foray into 'the sociolinguistics of ageing', and noted that sociolinguistics at that time had rather little to show by way of sustained research into later life or ageing per se. Overall, that remains true, particularly if we compare the space devoted to other age groups in sociolinguistic journals and textbooks. There is very little age-focused research that could, for example, bear comparison with the feminist perspectives that drove sociolinguistics forward during and after the I970s

* Centre for Language and Communication Research, Cardiff University, Cardiff, UK. 
(e.g. Lakoff I975; Hall and Bucholtz I995), or with contemporary linguistic ethnographies of class and race (e.g. Blommaert 2005; Rampton I995, 2006). When sociolinguists 'do' social class or gender or ethnicity, they very rarely overlay issues of ageing on their designs and questions. Most age-related sociolinguistics has to do with youth. Even when sociolinguists focus on 'change' (a topic which is still a mainstay of the discipline), it tends to be in a framework that highlights 'language change' rather than language as it is implicated in the processes of personal and social ageing. Ageing is still, in a general sense, the unwritten chapter of sociolinguistics.

This is changing, however, and it is striking how research in diverse social science and humanities disciplines is coming to recognise the importance of linguistic and communicative processes in how we understand ageing, particularly when ageing is viewed as a set of socially embedded processes and experiences. A social account of ageing needs to be sensitive to how language and communication are resources for making and reconfiguring what we take ageing to mean, either in commonsense terms (at the level of broad cultural assumptions and ideologies), or in very particular cases (at the level of individual identity and relationships, and how these are enacted at particular moments of social engagement). What is at issue is not just 'language' in a narrow sense, as with 'how do people of different ages speak?' or 'what patterns can we discern in intergenerational communication?' These are not uninteresting questions, but they are merely the surface of what we might call the discursive constitution of ageing. In that much wider agenda, researchers are interested both in the detail of local acts of meaning making and in how symbolic exchange through words and actions cumulatively contributes to social positions, norms and understandings about age-the micro-social connected through to the macro-social (as discussed by Nikander 2009 in this issue).

Each of the papers in this collection takes up a particular facet of the discursive construction of ageing, and reflects the current broadening and strengthening of discourse-analytic research on ageing. That is, while sociolinguistics itself arguably remains somewhat age-blind, the gap is being filled by important new work, not only from within the discipline but also by inter-disciplinary research that shares many of the foundational assumptions of sociolinguistics. Whether or not the authors brand themselves as sociolinguists (some would and some definitely would not) is far less important than their shared sensitivity to how age-salient meanings are constructed in talk and text, and therefore how social actors 'come to' or 'are brought to' what it means to be of a certain age in particular social environments.

One of the clear strengths of this perspective is its empirical foundation. While social theory and social gerontology are prone to generalisations

\section{CAMBRIDGE}


about ageing and society on the basis of survey data and different sorts of trend analysis, and sometimes from intuition alone ( $c f$. Nikander 2009), there is value in looking more closely at particular acts of meaning construction in situ. Through qualitative, contextually rich accounts, we can try to ground our claims and conclusions in primary data - in the social 'action' where age comes alive. If ageing is treated as something that we achieve in the minutiae of our social lives, in social encounters of diverse sorts and even in individual acts of expression in speech and writing, we may come to understand how social ageing (treated now as a matter of sociocultural norms, expectations, demands, constraints and opportunities) takes the forms it does. In taking a linguistically-grounded approach, we can therefore look outwards and upwards from the particular to the general, and in doing that we can examine the extent to which local experiences of age-related actions and interactions actually confirm or challenge what macro-social theories tell us contemporary ageing is like.

A related objective of fine-grained linguistic analysis is to build accounts that are as close as possible to social actors' own versions of events, wherever possible allowing informants to 'tell age' from their own perspectives and in relation to particular social moments and configurations, or else positioning the researcher as a recipient of age-related discourse - these ideas are discussed well by Bytheway (2009) in this collection. Put another way, language-based studies can 'give voice' to people as individual informants, in the manner pioneered in some aspects of Gubrium's research (e.g. Gubrium I993). This might help us avoid filtering research findings through the kinds of dense analytical and interpretive apparatuses that are associated with many other approaches and methods. Undeniably, there are different methodological orientations to 'language and ageing' research too, and linguistic analysis is no panacea. But the present papers all manage to give readers access to some 'first contact' linguistically mediated age experiences. These include the unstructured written, personal reflections of particular British people across different time-points (Bytheway 2009), conversations in family homes and conversational interviews with residents of a United States retirement community (Norrick 2009), conversational interviews with Finnish men and women aged around 50 years (Nikander 2009), the casual conversations of older Japanese women (Matsumoto 2009), and my own paper on the semantic constructions of magazine feature-writers and TV programme-makers (Coupland 2009).

We can be surprised when listening to and analysing age-related language - whether our own or other people's, and whether in our personal experience or as represented in research studies of the sort collected 
here. Often language gives pause for thought, if only because it confronts us with the great diversity of stances, experiences, identities and evaluations that are projected in the name of age-categories, like 'being middle-aged' or 'being old' (the main foci of this particular collection). Contemporary emphases in discourse analysis, interactional sociolinguistics and social pragmatics focus attention on the instability of social categories (see Jaworski and Coupland 2006 for an overview). Critical approaches to discourse (see Fairclough and Wodak 1997) emerged partly out of dissatisfaction with overly determined and determining social categories found in much empirical social research, as in studies that pre-define social groups by age-groups or sex and that seek to differentiate people into enshrined social groups.

Much early sociolinguistic research also used designs of this general sort. While social typologies can hardly be avoided when collecting or analysing survey data, close analysis of discourse generally shows that the social categories to which we are accustomed (as both researchers and lay observers and participants in social life) do not have the coherence and stability that we tend to assume. The ways in which we invoke 'being 50 ', for example, are often complex and may be mitigated or carefully contextualised. Many constructions are provisional expressions during extended negotiated sequences, and others are for some particular immediate purpose; whichever, they are unlikely to be full or final accounts of the meaning of being $5^{\circ}$ (Coupland 2000).

This observation accords with general theory in pragmatics (the study of how meaning accrues in practical activities of talk in social contexts). As Matsumoto (2009) explains in her paper, as a matter of principle communicative acts are only partially determined by their linguistic forms. Single utterances realise multiple and often conflicting communicative functions, and meaning emerges in the flow of discourse between multiple parties, often obliquely and inferentially. Not surprisingly then, acts of ageidentity through discourse often create multi-faceted and multiple images of and values for self and other. As Norrick (2009) establishes in his paper, when people narrate their own identities in talk, they construct different versions of themselves, not least because a story often requires someone to present themselves as the ' $I$ ' of the story-teller separately from the ' $I$ ' of the protagonist self - the self being 'storied'. In age terms, as in other regards, the narrativised self is therefore not necessarily uniform, and we have to accept that such coherence as does exist is a construction of the acts of telling (Linde I993, 2009). This is not to say that texts and discourses never construct particularised images and identities. My own paper focuses on age projections in media texts that I argue are unwarrantedly narrow and prejudicial. The apposite generalisation is that age-related

\section{CAMBRIDGE}


identities and age attributions are always matters of discursive contextualisation and their values have to be constructed and read relative to particular social contexts - particular communicative roles and relationships, particular architectures of situation, genre and purpose - and set against particular social norms and assumptions.

Unsatisfactory as this might sound in its complexity and relativism, it opens a window on different possibilities and definitions for individuals in their age categories and for ageing in general. A commitment to avoid over-determining age is probably an appropriate principle and prerequisite for gerontological research: as understanding of ageing and old age grows, an awareness of heterogeneity slowly supplants broad characterisations. While readers of this journal will be well informed about the real and sometimes depressingly real social correlates of old age, they will also be aware of the risk of over-generalising about age and the links between life-stage and experience in an increasingly complex and fluid social world. Later life is clearly not merely a matter of how it is talked into existence, a claim sometimes (simplistically) associated with Berger and Luckmann's (1966) thesis on the social construction of reality. Nor is it a prefigured condition that we enter and assimilate without agentive rights and opportunities, including to represent ourselves and our social relations with a degree of constructive freedom (Archer 2003). It might be that claims about 'agelessness' are themselves an articulation of a form of ageism (Andrews 1999), but old age is neither 'pre-discursive' nor 'extradiscursive' nor a matter of essential being. Nikander (2009) points to the contradictions and complexities of ageing in an increasingly globalised world, and a discourse analytic approach to social gerontology resonates with the potential openness and indeterminacy that this implies.

To this extent it would be interesting to explore how a language or discourse perspective in future research might contribute to the main themes that have been examined in recent years in Ageing \& Society. The journal has a strong record of publishing research on social policy, e.g. the problems and potential solutions of older people's housing, mobility, social exclusion, welfare and pensions; on care and social support, e.g. family structures, intergenerational relationships, care-giving by family members, and bereavement; on health, e.g. health promotion and life expectancy, coping with illness, falls, drug use or dementia; and on age-related lifestyles, e.g. older workers, post-retirement activity and wellbeing, religion and spirituality, quality of life, active ageing, stereotypes and ageism in advertising, body image and body work. For each of these broad topics, it is obvious that sociolinguistic and communication issues are important, but very few recent papers have taken an explicitly communicative or discursive approach. Many have acknowledged at some level that ageing 
achieves personal and social significance in the details of contextualised relationships and networks, individual variability is generally taken for granted rather than a matter for empirical inquiry. In some cases, even for researchers who are not linguists, there is no methodological alternative to collecting data in the form of written accounts or spoken interview responses. Under those circumstances, closer attention to the linguistic forms and functions of the data could be revealing. In other cases, research has addressed themes that are themselves defined in communicative terms, for example in relation to care-giving or social support. In such research, the question is whether a closer examination of text and talk might enrich analyses or yield more contextualised or indeed different findings.

The papers in this collection seek to demonstrate the sorts of insight that stem from a (broadly) sociolinguistic framing of research into ageing and old age. Using situated discourse as data, and qualitative methods of analysis, they focus on the role of language in shaping what is usually referred to, in category-bound terminology, as mid-life and late-life experience. The data that have been analysed are very diverse culturally and by situation, but the theories and methods are from a fairly unified pool, albeit one with various disciplinary labels: interactional sociolinguistics, narrative theory, critical pragmatics, social theory, discursive psychology and, of course, social gerontology itself. The focus in this issue is on change and how it associates with shifting age-identities, so emphasising how change is discursively interpreted and negotiated both by and for or about individuals in various social frames. The papers examine how individuals, as they move through the lifespan, negotiate their changing identities through talk-in-interaction, and through their production, reading and interpretation of texts. Change with age is something we commonly take for granted, but what do we make of these changes, and how do we find meaning in them? How do we and others relate to change, and how do we represent change and incorporate it into the impressions we give of ourselves to others, and of others to them?

A recent paper in this journal commented on the fluidity in social categorisation that the presented papers take as their starting point. Vincent (2007) focused on the potential for variation and variability in the experience of ageing, as afforded by age-related categorisation processes, such as what it means to be 50, 70 or 90 years of age:

Some aspects of the trajectory of social and biological changes over the lifespan are defined as 'ageing'. Age is also understood as a sequence of categories differentiated by specific criteria - including not least measures of chronology. Human cultures not only classify individuals and groups by 'age' but also develop normative expectations about 'ageing'. The specific content of these processes

\section{CAMBRIDGE}


and categories are contested and their meanings are not fixed. (Vincent 2007: 943)

Our biological and chronological ageing are, in objective terms, immutable and indisputable, at least until we start to see chronology as a socially created and endorsed meaning system, and until we realise that biological ageing is only one of several metrics that we can impose on ourselves and others (as discussed in my later paper). Objective metrics need to be interpreted and recontextualised by the stances people take on ageing (Coupland and Coupland 2009), and the social experience of ageing and change is constituted by acts of self- and other-positioning (Harré I983), which brings us back to discourse (see Nikander 2009). We are both constrained and enabled through our engagement with cultural scripts about ageing, and the textual reflexes of such scripts are available as data of different sorts - in reflective autobiographical accounts, in private conversations, in more public discourses, and in mass-media texts and images.

The interface between discourse and identity is a central concern of all the papers that follow. But age-identity is not separable from other social dimensions in which identities are constructed or attributed, such as gender, sexuality, class, culture, religion, nationality and profession. A discourse-analytic approach assumes that identities are complexes of meaning potential, waiting to be triggered or activated or made salient under particular circumstances and in the flow of social life and social interaction. As Blommaert put it:

Almost any significant author in the wide field of identity studies would argue that people don't have an identity, but that identities are constructed in practices that produce, enact, or perform identity - identity is identification, an outcome of socially conditioned semiotic work. (2005:205)

In this framework, analysts need to track the processes of social identification that emerge in linguistic data, rather than come to texts and contexts with a pre-defined taxonomy of social types and attributes. The perspective assumes that social identification is a form of social action or 'work' that: (a) takes place in specific social settings whose constitution needs to be worked through as part of the analysis; (b) yields shifting constellations of identities, instead of individual, monolithic identity categories; (c) does not simply inhere in and emanate from an individual person, but results from processes of negotiation and an interplay of voices and authors; (d) involves processes of 'entextualisation' (generating meaningful 'texts of identity') and often 're-entextualisation' (revising and reformatting earlier versions of a social identity, perhaps deriving from earlier texts of cultural scripts). In short, then, identity is treated as the

\section{CAMBridge}

\section{JOURNALS}


product of particular forms of 'discursive work' (De Fina, Schiffrin and Bamberg 2006: 2). People are simultaneously the products and the producers of discourse, and language is treated as both a constraining and an enabling resource.

The five papers in this thematic issue bring this general framework to bear on very different types of data. Written primarily from a discursive psychology perspective, Pirjo Nikander's paper nevertheless gives us a very useful and comprehensively referenced overview of major discourse-based approaches to the study of age identity. It therefore serves well as a further introduction to the collection. Nikander explains the basis of constructionist theory in this area, and the importance of going beyond fixedcategory conceptions of age-identity. Her principal research question in this paper is how Finnish people close to their 5oth birthdays (bearing in mind that the 50 birthday seems to be particularly marked institutionally in Finland) orient to the 'condition of ageing' in their talk. Looking critically at interview data, she finds recurrent patterns, particularly in relation to how interviewees express temporal relations when they comment on and make sense of the chronologically specific theme of 'being 50'. A discursive 'device' labelled the expression of 'provisional continuity' is identified, when speakers acknowledge the likelihood or even the inevitability of change with ageing (in expressions such as 'this is still quite a good age', where the adverbial 'still' carries a wealth of implications about 'normal decremental ageing'). Yet in using formulations of this sort, speakers also often deny the relevance or impact of ageing to themselves at these moments. Nikander's analysis then reveals more detailed rhetorical patterns through which the complex relational meaning of 'provisional continuity' is expressed by several informants.

Beyond her paper's particular empirical contribution, Nikander debates the constitutive role of language in relation to age identity. While acknowledging that we have shared cultural resources for defining and thematising age, her work shows, through studying interaction and textual practices, how constructionism challenges the notion that ageing is 'the same' for all people at all times and in all situations. She finds, for example, that her interviewees 'endlessly reshuffle' culturally-familiar images of ageing. The general point is that discourse data help us refine generalist claims about, for example, whether people subscribe to decremental models of ageing, agelessness, uni-age culture and other simplifying concepts. At the level of discursive practice, ageing proves not to be lived out in such categorical ways.

Bill Bytheway uses the rare resource of longitudinal data on birthday celebrations from the British Mass-Observation Archive to examine individual respondent's written representations of their own ageing in the

\section{CAMBRIDGE}


context of life continuities and life changes. The data allow a comparative analysis of informants' accounts of the marking of their own birthdays I2 years apart, from written accounts produced in I990 and 2002. The accounts are idiosyncratic and personal, and many are moving or evocative and tantalising as regards age identification. Age proves not to be widely referred to except in rather formulaic ways. Yet a sense of what it means to celebrate a birthday at different points in one's life begins to emerge from the 55 time-paired reports that were available. Bytheway draws attention to how the accounts can be read as data on sociocultural change (or the 'period' effect) as well as personal lifespan change (the 'age' effect), and how these temporal dimensions interconnect in particular selfaccounts. The birthday narratives delineate changes which are in some ways age-ordered; for example, they track the changing generational structure of families. For middle-aged informants, this includes talk of the death of parents, of children leaving the family home, and of the birth of grandchildren. For older informants, it includes accounts of the death of a partner or close friend. The texts reveal some shifting priorities that people have in relation to specific ways of marking birthdays and celebrations with family or friends - the onset of chronic illness in loved others or changes in mobility (e.g. the decision to stop driving) play their part in this - but there is also much common ground and continuity in the accounts. The respondents' representations of personal and family changes and their life implications in these snippets of personal biography stand as fundamentally ordinary, domestic portrayals of the crossing of age boundaries and they feature individual preferences and practices. The data give us intimate glimpses of contentment and sadness as the informants moved through their lives.

Neal Norrick's paper is also based on narrative accounts, and examines the personal stories told during interviews by people in their eighties. The analytic focus is on how old people discursively construct their earlier, different, selves, in the tradition of Charlotte Linde's Life Stories (Linde I993). Norrick's analysis gives us a way of responding to one of the most fundamental and captivating questions in age-identity research, namely as we age, in what meaningful sense are we the product of our earlier selves? Discourse analysis of extracts from these stories enables Norrick to show how the story-tellers make age-relevant meanings in two rather different ways, through strategic impression management (in Goffman's terms, signs that are 'given'), and through less conscious and controlled impressions (Goffman's signs 'given off'). Their current and projected (former) identities are portrayed as different and sometimes dissonant. Some self-portrayals involve self-association with the past and dissociating the teller's present identity from past identities ( $c f$. Coupland, Coupland 
and Giles 199I). This relativising of 'I' and 'me' over time is a primary resource for negotiating personal change in the context of sociocultural change. Norrick talks of 'retrospective reassessment', in which a present self may not represent the 'full' identity or identities that a narrator can relevantly construct. The plea by one of his informants, 'please don't judge me by my present frail state', is a telling invocation of the ability of such narratives to bridge between multiple identities occasioned by age and change.

The discourse of older people's narratives can itself be highly revealing about age-related fears and competences at the point of telling, as when some of Norrick's informants remarked on their 'senior moments' when they failed to remember details of past events. Cognitively-oriented research makes considerable play of linguistic and discursive 'failings' in later life, and of course we need to test generalisations about linguistic and communicative competences at different lifespan positions. Norrick's emphasis is to point to the social functioning of remembering and forgetting in narrative performance, when the challenge in relating one's own life through imperfectly remembered episodes is to reassess oneself relative to one's lived experiences, activities, friends and families. He shows that there are moments of exceptional clarity in storied remembering, when a speaker makes fresh reassessments of his or her achievements and failings, but also of where s/he stands developmentally at the time of telling.

The observation that older people's talk is revealing, both theoretically and empirically, and often surprising and even emancipating is shared by Yoshiko Matsumoto. Her paper focuses on the apparently depressing phenomenon of older people's 'troubles talk', or what colleagues and I referred to in earlier work as 'painful self-disclosure' or 'PSD'. The specific context is older Japanese women talking about their husbands' illnesses and deaths. Matsumoto recorded the informants' extended conversations on this theme with friends and close acquaintances. The discursive focus of her paper is on humour and on the apparent contradictions in 'painful but humorous' narratives of personal loss. Humour and laughter in talk are of course multi-functional, and earlier studies ( $c f$. Jefferson ${ }^{1984}$ ) have made the point that laughter can provide a means of mitigating face-threatening talk or showing that a speaker is relatively impervious to the 'painfulness' of a recounted episode, and in that sense 'troubles-resistant'. Matsumoto's closely observed commentary suggests that the laughter in the older Japanese women's conversations functions to shift the status of troubles told - to downgrade bereavement to the status of a quotidian event. In a two-directional process, laughter downgrades the focal event, and the apparent incompatibility of bereavement and laughter is therefore dissolved.

\section{CAMBRIDGE}


As in Nikander's analysis, Matsumoto goes on to show that the discursive negotiation of 'painful but humorous' themes needs to be handled with extreme delicacy. The participants have to make precisely timed contributions to co-constructed narratives, using appropriate emotional tones and keys. Listeners have to formulate their own laughter at appropriate moments in order to support the 'painful but humorous' design that a teller has introduced, and they also need to express empathy at critical moments. The painful but humorous stories were accomplished through sophisticated and subtle discursive routines. The pertinent methodological point is that sociolinguistic perspectives on ageing and age identity demand analytical sensitivity and sophistication if they are to reveal the full dynamics of acts of social construction, because the negotiation of agemeanings in discourse and of identity change is itself a sophisticated complex of social actions. In Matsumoto's data, 'reclaiming normality' for older speakers is not a simple matter of 'what one says'; it is a possible achievement of finely-tuned communicative actions in particular social settings. As indicated in Bytheway's paper, Matsumoto shows that for discursive identity shift intentions to function adequately, the speaker needs to be heard and supported. What we might otherwise dismiss as 'just small talk' justifies an audience, both relationally (amongst peers) and academically (as a focus of research inquiry).

My own later paper differs from the others in that the focus is massmediated data. The written data are from a corpus of lifestyle magazines targeted at women, and the specific interest is how magazine texts represent changes in women's bodily appearance. The age-focus is midlife, in the sense that the sample of magazines mainly targets 'middleaged' women, while also setting out normative positions on 'what women should look like' at various ages. Change is very much the focus, partly because women are urged to make changes to their projectable, visible identities, or indeed to 'resist change' in the sense of taking steps to 'avoid the ravages of time' and thereby protect the symbolic capital invested in bodily appearance. Decade-based temporality is very much in evidence, as in the title and slogan of the TV programme Ten Years Younger that is closely examined. It is one of the genre of 'makeover' programmes that are currently in vogue, and makes much use of the decade as a unit of personal time as well as social change ( $c f$. interesting points about 'decabirthdays' are also made in Bytheway's paper). In Ten Years Younger, we find discursive models of ageing that treat 'normal' biological ageing as decremental and problematic, and which purport to be able at a price to 'turn back time' through technological solutions.

Data of this sort make it clear that age-identities in mid-life are not exclusively matters of private assessment or intimate dialogues among 
friends and peers. What it means to be, say, 50 can be taken up in normative, prejudicial discourses in which the speakers seek to impose their own criteria and ideological values on others. Reviewing the themes and arguments in all five papers, one might say that age-identity and change are in many different regards negotiated at the intersection of private and public domains. Identity work necessarily involves a movement between a personal narrative or 'project' and wider social and ideological formations that propose frameworks of understanding and meaning that influence our sense of our own and other people's ageing. Identity might itself be best thought of as a relational process, a dialogue between 'who we are' and who, in the social frames we are exposed to, we might be expected to be. The discursive perspective that is advanced by the authors of the following papers is well suited to capturing this relationality with the attention that is required to the details and subtleties of strategies and devices of biographical talk.

\section{References}

Andrews, M. 1999. The seductiveness of agelessness. Ageing \& Society, 19, 3, 30I-18.

Archer, M. S. 2003. Structure, Agency and the Internal Conversation. Cambridge University Press, Cambridge.

Berger, P. and Luckmann, T. ig66. The Social Construction of Reality. Penguin, Harmondsworth, UK.

Blommaert, J. 2005. Discourse. Cambridge University Press, Cambridge.

Bytheway, B. 2009. Writing about age, birthdays and the passage of time. Ageing \& Society, 29, 6, 88I-99.

Coupland, J. 2000. Past the 'perfect kind of age'? Styling selves and relationships in over-fifties dating advertisements. Fournal of Communication, 5o, 3, 9-30.

Coupland, J. 2009. Time, the body and the reversibility of ageing: commodifying the decade. Ageing \& Society, 29, 6, 95 ${ }^{\mathrm{I}-75}$.

Coupland, J. and Coupland, N. 2009. Attributing stance in discourses of body shape and weight loss. In Jaffe, A. (ed.), The Sociolinguistics of Stance. Oxford University Press, New York, 227-49.

Coupland, N., Coupland, J. and Giles, H. 1991. Language, Society and the Elderly: Discourse, Identity and Ageing. Basil Blackwell, Oxford.

De Fina, A. Schiffrin, D. and Bamberg, M. (eds) 2006. Discourse and Identity. Cambridge University Press, Cambridge.

Fairclough, N. and Wodak, R. I997. Critical discourse analysis. In van Dijk, T. (ed.), Discourse as Social Interaction. Volume 2, Sage, London, 258-84.

Gubrium, J. 1993. Speaking of Life: Horizons of Meaning for Nursing Home Residents. Aldine de Gruyter, Hawthorne, New York.

Hall, K. and Bucholtz, M. (eds) i995. Gender, Articulated Language and the Socially Constructed Self. Routledge, London.

Harré, R. i983. Personal Being. Basil Blackwell, Oxford.

Jaworski, A. and Coupland, N. (eds) 2006. The Discourse Reader. Routledge, London.

Jefferson, G. ig84. On the organization of laughter in talk about troubles. In Atkinson, J. M. and Heritage, J. (eds), Structures of Social Action. Cambridge University Press, Cambridge, $346-69$.

\section{CAMBridge}


Lakoff, R. 1975. Language and Women's Place. Harper and Row, New York.

Linde, G. I993. Life Stories. Oxford University Press, New York.

Linde, C. 2009. Working the Past: Narrative and Institutional Memory. Oxford University Press, Oxford.

Matsumoto, Y. 2009. Dealing with change: humour in painful self disclosure by elderly Japanese women. Ageing \& Society, 29, 6, 927-50.

Nikander, P. 2009. Doing change and continuity: age identity and the micro-macro divide. Ageing \& Society, 29, 6, 86I-79.

Norrick, N. 2009. The construction of multiple identities in elderly narrators' stories. Ageing E Society, 29, 6, 90I-25.

Rampton, B. 1995. Crossing. Longman, London.

Rampton, B. 2006. Late-Modern Language, Interaction and Schooling. Cambridge University Press, Cambridge.

Vincent, J. A. 2007. Science and imagery in the 'war on old age'. Ageing \& Society, 27, 6, 94I-62.

Address for correspondence:

Accepted 9 December 2008

Justine Coupland, Centre for Language and Communication Research, Cardiff University, Humanities Building, Colum Drive,

Cardiff CFio $3 \mathrm{EU}, \mathrm{UK}$.

E-mail: CouplandJ@cf.ac.uk 